\title{
Residual Stress Distribution in Butt Flat Welded Joint of High Strength Steel
}

\author{
Qianqian Jia, Gong Chen
}

\begin{abstract}
Modern ships and offshore engineering structures are usually welded by a large number of high-strength steel, and flat plate butt welding joint is the most common joint form in ship structures. These welded joints inevitably produce welding residual stress during welding process and have an impact on the fatigue strength of the whole structure, while high strength steel is more sensitive to welding residual stress. At the same time, due to long-term alternating loads caused by waves, waves and currents during service, the weld zone is prone to cracks, which will lead to fatigue fracture of the structure. In this paper, based on the theory of thermo-elastic-plastic and fracture mechanics, the residual stresses of welded joints of high strength steel plate are studied by programming with APDL language in ANSYS, and the distributions of residual stresses in different paths are obtained. The results show that the peak value of transverse residual tensile stress appears near the weld toe, while the stress far from the weld is relatively small. The research results in this paper can lay a foundation for the fatigue life study of ship welded structures.
\end{abstract}

Index Terms - Residual Stress, High-Strength Steel, Numerical Simulation, butt flat welded joint.

\section{INTRODUCTION}

Nowadays, high strength steel is widely used in many ships and marine structures in the form of welded structures. During the welding process of these structures, the weld metal is melted by high temperature which exceeds its melting point, and uneven distribution of welding residual stresses occurs in the structure after solidification and cooling. This leads to the inaccuracy of the single theoretical method in the prediction of welding residual stresses, while the experimental method is far from enough. Limited by high costs, it is also difficult to achieve. With the continuous development of finite element software and computer technology, many scholars began to use numerical simulation method to study residual stress.

Brickstad and Josefson [1] studied butt welding of stainless steel pipes with relatively large diameter by numerical simulation. The composite effect of temperature field and stress field was considered from many angles. The sensitivity of welding process parameters to residual stress was studied concretely and completely. Papazoglou [2] et al. simulated the phase transformation problems that may exist in the welding process of medium and heavy plates, and took into account the factors that may influence the simulation, such as the surface radiation of thick plates. Chin-Hyung Lee [3] et al. simulated the residual stress field of steel plates with different material properties. It was found that with the increase of

Qianqian Jia, School of Naval Architecture and Ocean Engineering, Jiangsu University of Science and Technology, Zhenjiang 212003, China.

Gong Chen, School of Naval Architecture and Ocean Engineering, Jiangsu University of Science and Technology, Zhenjiang 212003, China. yield strength, the peak value of longitudinal residual stress would increase, and there was a positive correlation between them. Deng [4] studied the welding deformation and stress of low and medium carbon steel plates during butt welding, and considered the effect of solid phase transformation. The results show that the effect of solid phase transformation on carbon steel butt welding is related to carbon content. The effect on low carbon steel can be neglected because it is small, while the effect on high carbon steel can not be neglected. Wang Jianhua [5] et al. used three-dimensional thermo-elastic-plastic analysis method to analyze the dynamic stress and strain in welding process and the residual stress and strain after welding by numerical simulation. Through comparison, it is found that the simulation of welding temperature field is a typical non-linear transient heat conduction problem, and an improved method is proposed to improve the accuracy of three-dimensional transient welding temperature field solution. Luanli [6] et al. specially studied the welding process of thick plate, and completed the simulation of the stress and strain fields.

Based on the theory of thermo-elastic-plastic, the welding residual stresses of butt-welded plate model of high strength steel were numerically simulated by life-death element method.

\section{BASIC THEORY}

\section{A. Welding temperature field}

The change of temperature field is a non-linear transient heat conduction problem [7]. In the change of temperature field, it can be found that the heat transfer occurs when the welding starts, which leads to the change of temperature of the whole welding part with time and different positions. In addition, the properties of the material would also change, such as melting and phase transformation phenomena due to high temperature. The following formula can be derived for the transient heat conduction of materials with the same properties in all directions:

$c \rho \frac{\partial T}{\partial t}-\frac{\partial}{\partial x}\left(k \frac{\partial T}{\partial x}\right)-\frac{\partial}{\partial y}\left(k \frac{\partial T}{\partial y}\right)-\frac{\partial}{\partial z}\left(k \frac{\partial T}{\partial z}\right)-\frac{\partial Q}{\partial t}=0$ (1) Where $c$ represents the specific heat capacity; $\rho$ represents the density; $T$ represents the temperature distribution; $k$ represents thermal conductivity; The parameters $k, \rho$ and $C$ all change with temperature. When the temperature change in $z$ direction is assumed to be zero in a certain direction, equation (1) degenerates into a two-dimensional heat conduction differential equation:

$c \rho \frac{\partial T}{\partial t}-\frac{\partial}{\partial x}\left(k \frac{\partial T}{\partial x}\right)-\frac{\partial}{\partial y}\left(k \frac{\partial T}{\partial y}\right)-\frac{\partial Q}{\partial t}=0$ 


\section{B. Welding stress field}

At high temperature, the material will undergo plastic deformation during welding, which results in the change of stress-strain relationship with the change of temperature. The linear relationship between the two is expressed as follows:

$d \sigma=D d \varepsilon-C d T$

Where $d \sigma$ represents the stress increment and $d \varepsilon$ represents the strain increment; $D$ represents an elastic or plastic matrix; $C$ represents a vector related to temperature; $d T$ represents a temperature increment.

\section{NUMERICAL SIMULATION OF RESIDUAL STRESS IN BUTT FLAT WELDED JOINTS OF HIGH STRENGTH STEEL}

A. Numerical simulation and analysis process of welding residual stress
The numerical simulation of welding residual stress can be simplified to the numerical calculation of instantaneous temperature field and the numerical analysis of instantaneous stress and strain field. The temperature field of the whole welding process is calculated based on the theory of thermal-elastic-plastic. Then, based on the calculation results of temperature field, the whole welding residual stress and strain field are obtained. The finite element analysis method includes direct coupling method and indirect coupling method. In this paper, the indirect coupling method is used, which ignores the effect of deformation heat on the temperature field in the residual stress field and only considers the coupling of the temperature field to the residual stress field. Fig. 1 gives a relatively complete calculation anda analysis process.First Author personal profile which contains their education details, their publications, research work, membership, achievements, with photo that will be maximum 200-400 words.

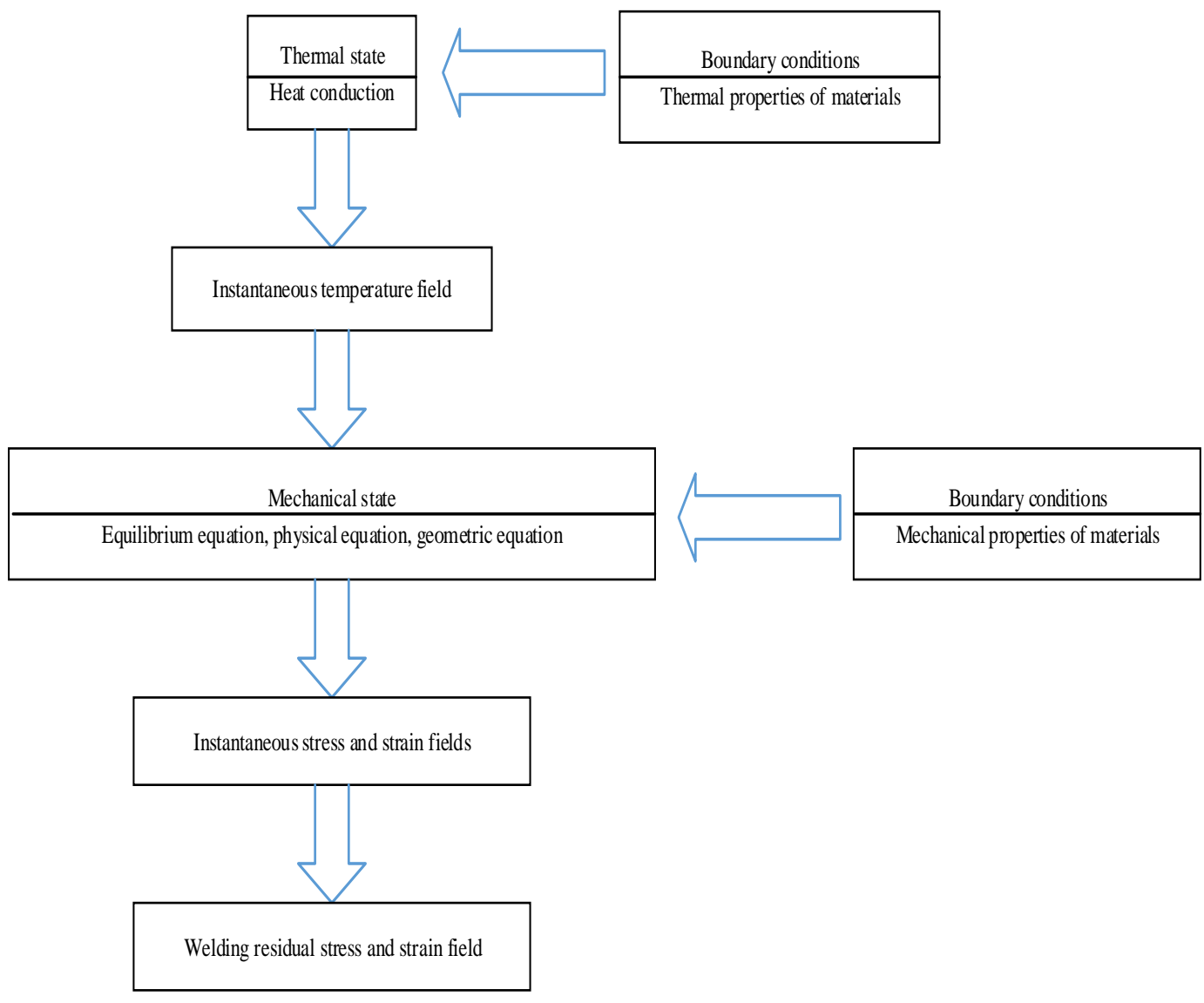

Fig. 1. Flow chart of finite element analysis

\section{A. Research object and size}

Butt flat welded joint of high-strength steel is formed by butt welding of two plates with the size of $250 \mathrm{~mm} \times 125 \mathrm{~mm} \times 38$ $\mathrm{mm}$. The weld size is simplified to $250 \mathrm{~mm} \times 10 \mathrm{~mm} \times 38 \mathrm{~mm}$. The weld length is the same as that of two base metal plates. The origin of the three-dimensional coordinate system $(0,0$, 0 ) is set at a corner of the steel plate of model. The X-axis of the three-dimensional coordinate system is perpendicular to the length of the weld, the Y-axis is along the length of the weld, and the $\mathrm{Z}$-axis is along the depth (thickness) of the weld. The geometric model is shown in Fig. 2.

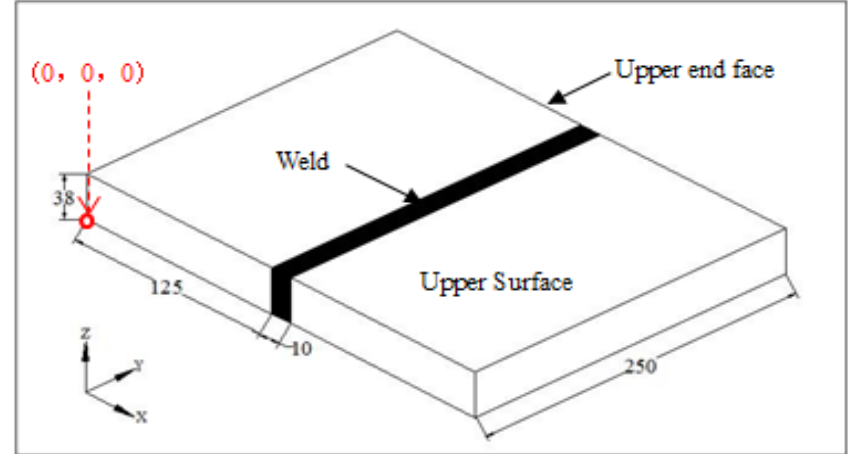

Fig. 2. Geometric model and dimension of the model(mm). 


\section{B. Finite element model and welding process parameters}

In this paper, the life and death element technology is used to simulate the welding process. The initial temperature is set as the room temperature of $25^{\circ} \mathrm{C}$ and the welding throat temperature is $1300^{\circ} \mathrm{C}$ and the convective heat transfer coefficient is $62.5 \mathrm{~W} / \mathrm{m}^{2}$. The weld zone is simplified to 5 layers [8], which are welded alternately from the middle to both sides. The welding time of each layer is 240 seconds, the heating and cooling time ratio is 1:11 [9], and the overall cooling time is 6000 seconds. Because the weld and its surrounding heat affected area are the focus of the research, the mesh of the weld and its surrounding area is refined when meshing the finite element model. In order to increase the efficiency and shorten the calculation time, the mesh generation is sparse in the area far from the weld seam. When the residual stress field is simulated and analyzed, the boundary conditions are fixed rigidly at four corners to avoid displacement. The finite element model and boundary conditions are shown in Fig. 3.

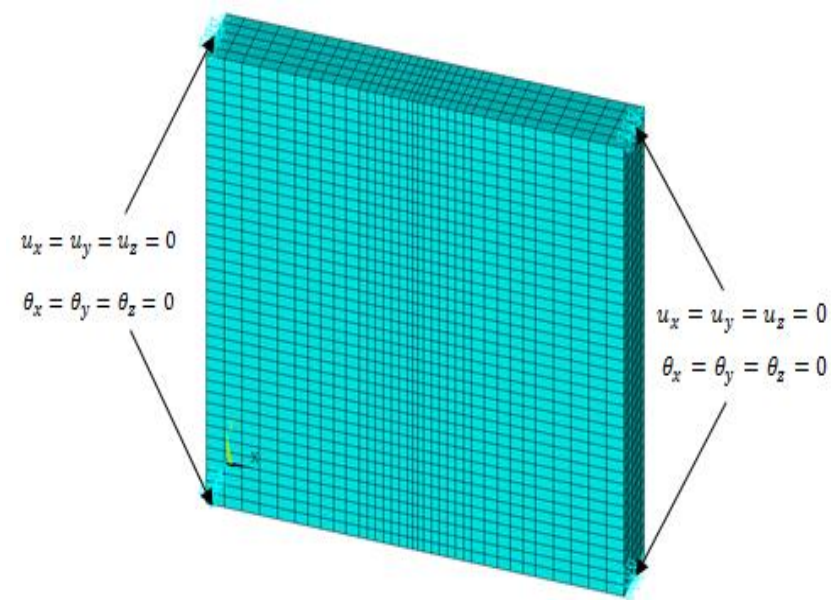

Fig. 3. Finite element model of the whole model

\section{Material parameters}

The material of the butt flat welded joint model is a high-strength steel. Its modulus of elasticity is $1.96 \times 10^{5}$ $\mathrm{MPa}$, Poisson's ratio is 0.3 , and its yield strength is about 918 $\mathrm{MPa}$. Material at the weld seam is usually welded by material similar to the base metal. Therefore, in this paper, the weld material is also set as the same high strength steel in the finite element simulation process. The material properties at different temperatures are shown in Table I and the mechanical properties are shown in Fig. 4

Table I . The material properties of high tensile strength steel.

\begin{tabular}{llllll}
\hline $\begin{array}{l}\text { Temp } \\
\text { eratur }\end{array}$ & $\begin{array}{l}\text { Elastic } \\
\text { modulus } \\
\mathrm{MPa}\end{array}$ & $\begin{array}{l}\text { Poiss } \\
\text { on's } \\
\text { ratio }\end{array}$ & $\begin{array}{l}\text { Thermal } \\
\text { expansion } \\
\text { coefficient } \\
K /\left(1 /{ }^{\circ} \mathrm{C}\right)\end{array}$ & $\begin{array}{l}\text { Heat } \\
\text { transfer } \\
\text { coefficie } \\
\mathrm{nt} \\
\lambda /(\mathrm{W} /(\mathrm{m} \cdot\end{array}$ & $\begin{array}{l}\text { Specific } \\
\text { heat }\end{array}$ \\
$\begin{array}{l}{ }^{\circ} \mathrm{C} \\
\mathrm{o} \mathrm{C}))\end{array}$ & $\begin{array}{l}\mathrm{C} /(\mathrm{J} / \\
\left.\mathrm{kg} \cdot{ }^{\circ} \mathrm{C}\right)\end{array}$ \\
\hline 25 & $1.96 \mathrm{E}+5$ & 0.3 & $1.2 \mathrm{E}-5$ & 16.3 & 450 \\
500 & $1.4275 \mathrm{E}+5$ & 0.3 & $1.58 \mathrm{E}-5$ & 16.3 & 707 \\
1000 & $0.7575 \mathrm{E}+5$ & 0.3 & $1.72 \mathrm{E}-5$ & 16.3 & 1370 \\
1300 & $0.0425 \mathrm{E}+5$ & 0.3 & $1.86 \mathrm{E}-5$ & 16.3 & 6800 \\
\hline
\end{tabular}

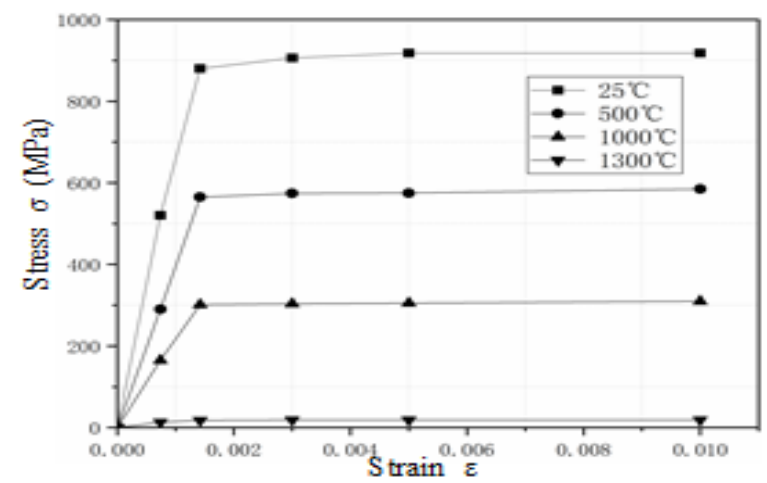

Fig. 4. Stress and strain for the high tensile strength steel under different temperatures

\section{Numerical simulation results of temperature field}

The distribution of temperature field at the completion of each layer of bead heating and at the middle and late stages of overall cooling is taken as several typical moments, as shown in Figs. 5 and 6

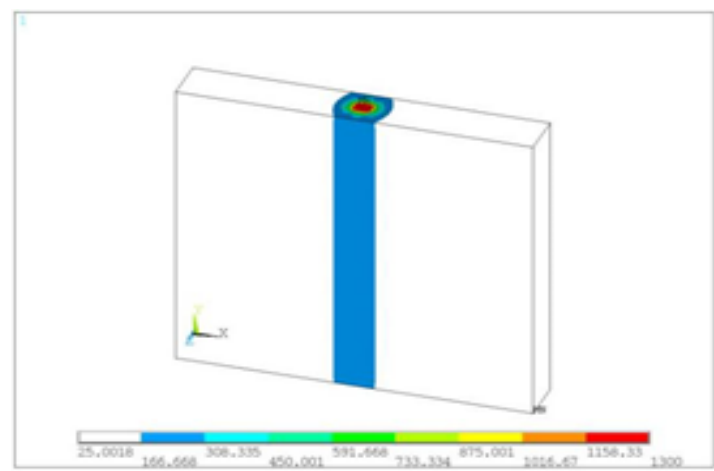

(a) $t=20 \mathrm{~s}$ (First pass welding)

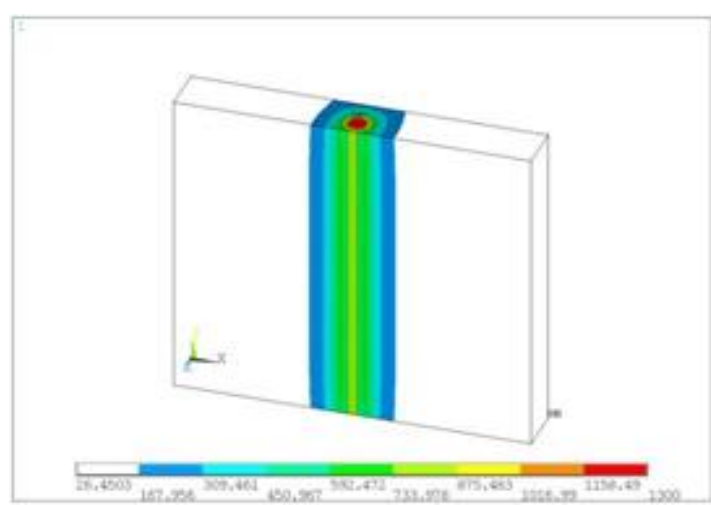

(b) $t=260 \mathrm{~s}$ (Second pass welding)

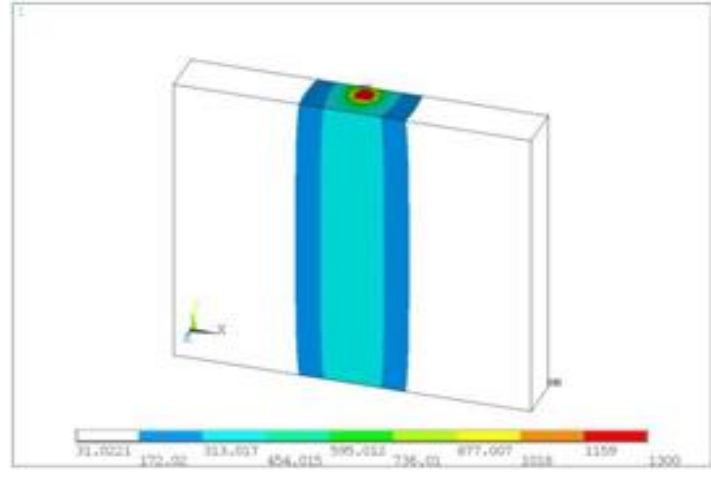

(c) $t=500 \mathrm{~s}$ (Third pass welding) 


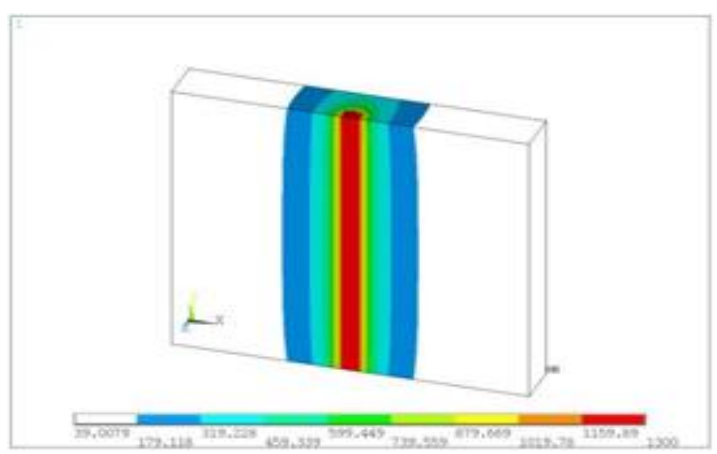

(d) $t=740 \mathrm{~s}$ (Fourth pass welding)

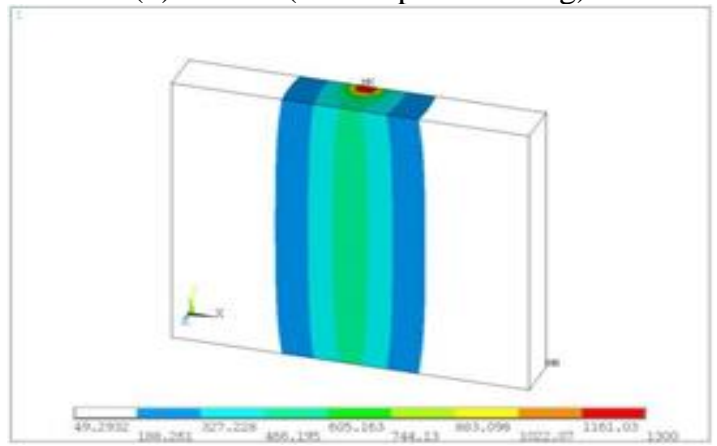

(e) $t=980 \mathrm{~s}$ (Fifth pass welding)

Fig. 5. The temperature field in the process of welding

According to Fig. 5, the distribution of temperature field during welding heating can be seen as follows:

(1) During the welding process, the highest temperature of welding appears on 1-5 layers of weld bead in turn, and after each layer of weld bead is completed, the highest temperature reaches $1300 \mathrm{C}$, which is the temperature of weld throat;

(2) With the increase of welding time, the heat generated by filling and heating of the weld diffuses from the center of the weld (the highest temperature) to the left and right ends of the model, and the heat affected zone of the weld expands continuously

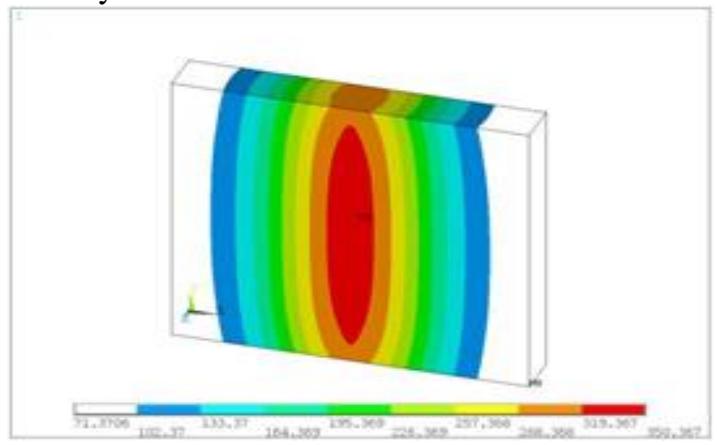

(a) $\mathrm{t}=2400 \mathrm{~s}$

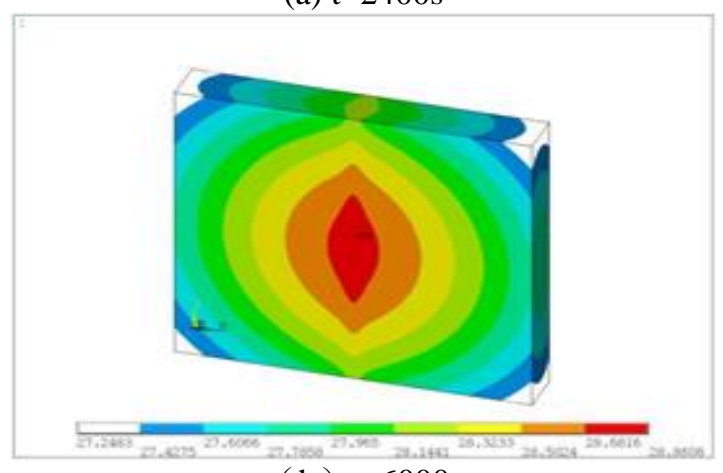

(b) $\mathrm{t}=6000 \mathrm{~s}$

Fig. 6. The temperature field of the model in the process of cooling after welding.
According to Fig. 6, the distribution of temperature field during the whole cooling process after welding can be seen as follows: (1) After the five layer beads are finished and turn into the overall cooling, the maximum temperature in the temperature field decreases significantly, and the heat affected zone of the welding is further expanded, but the maximum temperature is still concentrated in the weld zone. At the same time, compared with the two ends of the weld, the temperature of the center of the weld is higher, and the temperature of the upper and lower ends of the weld is cooled faster.

(2) The temperature gradient of the whole welded joint decreases obviously after the whole cooling period, and gradually cooled to room temperature of $25 \mathrm{C}$.

\section{E. Results of numerical simulation of residual stress field}

The initial welding residual stress field of model is simulated by indirect coupling method, and the distribution of welding residual stress is obtained after calculation. The results include transverse ( $\mathrm{X}$ direction) welding residual stress and longitudinal (Y direction) welding residual stress. This paper will focus on the study of transverse (X direction) welding residual stress. Fig. 7 and Fig. 8 are the distributions of transverse and longitudinal welding residual stresses of plate model, respectively

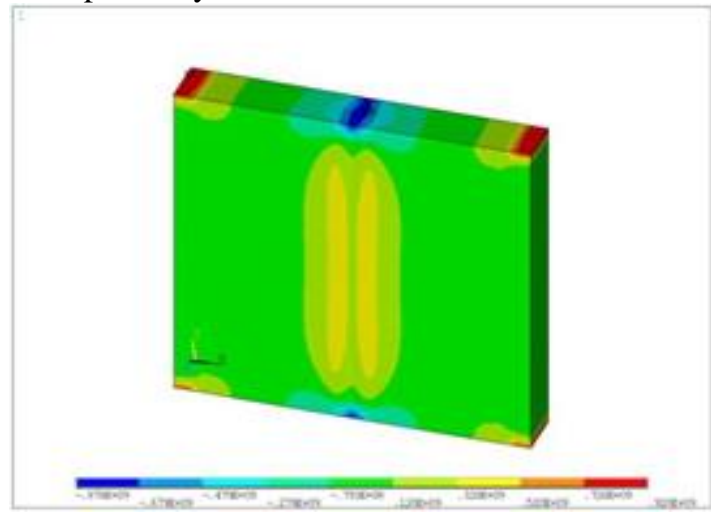

Fig. 7. Distribution of transverse residual stress

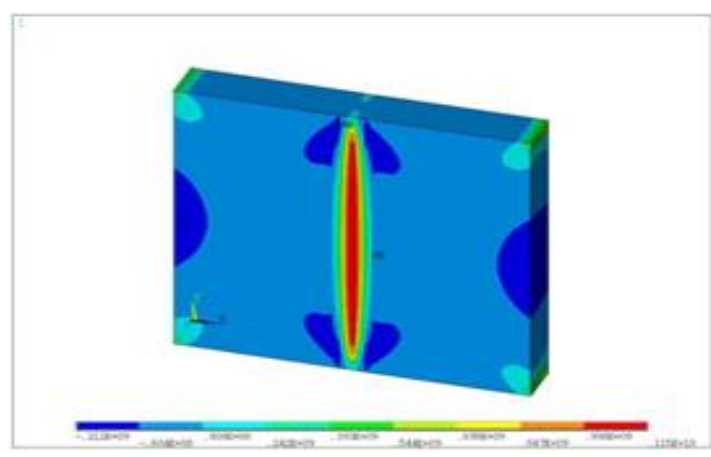

Fig. 8. Distribution of longitudinal residual stress

From Figs. 7 and 8, it can be seen that the residual tensile stress near the weld is large and the stress gradient is large, while the area far from the weld is the compressive stress distribution, and the stress gradient is small. The rigid fixing of four corner edges of welded joint results in stress concentration after welding. In addition, due to the influence of edge effect, large residual compressive stresses are formed at the upper and lower ends of the weld.

In order to visualize the variation and distribution of residual stress around the weld of model, two different analysis paths are defined on the upper surface of model 1, as shown in Fig. 
9. Path 1 is located on the surface of the plate parallel to the weld; Path 2 is located on the surface of the plate perpendicular to the weld

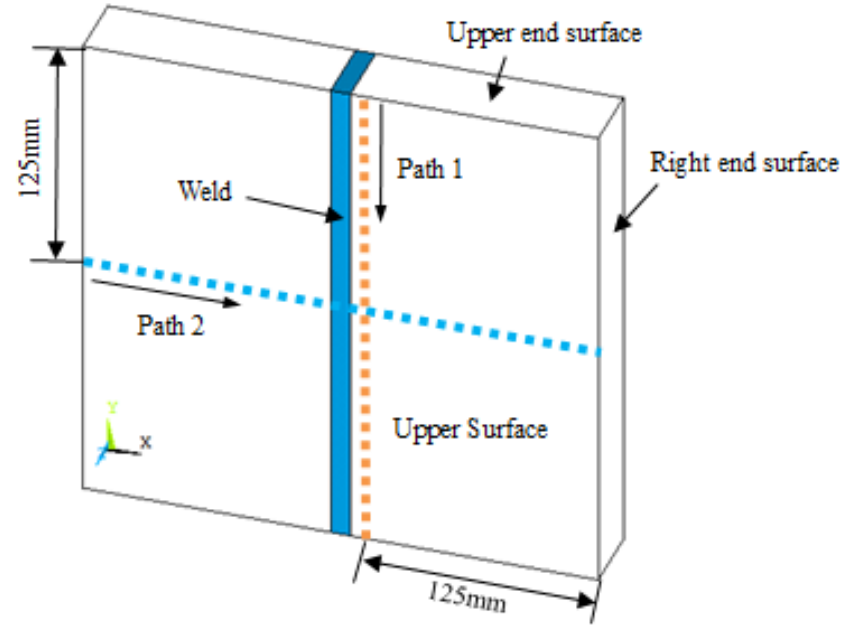

Fig. 9. The definition of the path 1 and path 2

The distribution of transverse welding residual stress and longitudinal welding residual stress under paths 1 and 2 is shown in Fig. 10

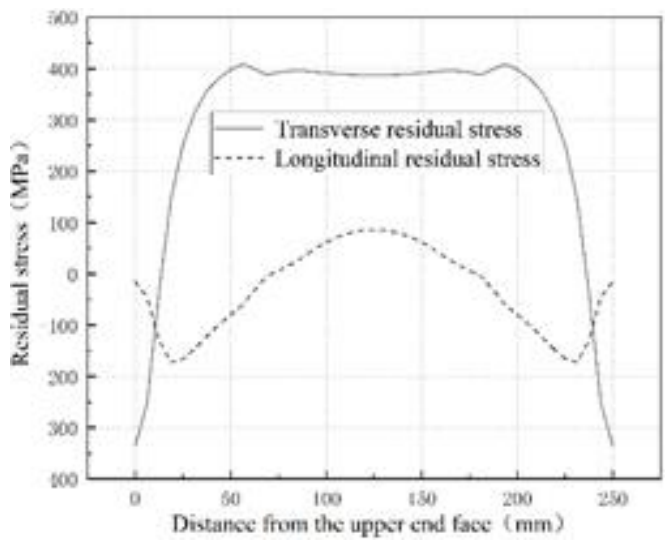

(a) Path 1

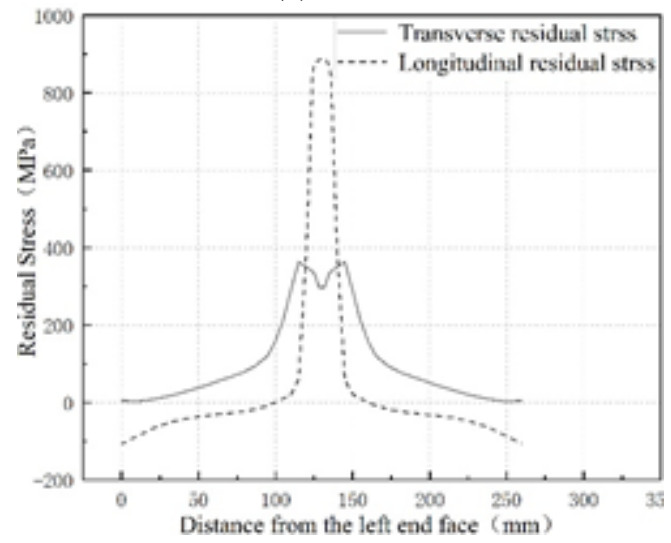

(b) Path 2

Fig. 10. Distribution results of residual stress under the two paths

According to the results of Fig. 10, it can be seen that:

(1) There are large transverse residual tensile stresses in most areas along the parallel weld direction (path 1), with the maximum value reaching $402 \mathrm{MPa}$, and the trend of stress variation near the weld center is gentle. Longitudinal residual tensile stress reaches its maximum value at the center of the weld, which is $90 \mathrm{MPa}$. The tensile stress decreases gradually in the transition zone from the weld center to the upper and lower ends of the model.

(2) On the vertical weld direction (path 2), the results of transverse welding residual stress show a bimodal curve distribution. The maximum tensile stress at the two peaks is $363 \mathrm{MPa}$, symmetrically distributed along both sides of the weld, $10 \mathrm{~mm}$ away from the weld, and the maximum residual tensile stress appears at the center of the weld.

\section{CONCLUSION}

Based on the theory of thermo-elastic-plastic, the numerical simulation of residual stress in butt welding model of high strength steel plate is studied in this paper, and the conclusions are drawn as follow:

(1) Along the weld direction, the transverse welding residual tensile stress is larger in the center of the weld and its vicinity, and the trend of stress change is gentle. In the transition zone from the center of the weld to the upper and lower ends of the weld, the tensile stress decreases gradually, and the peak value of the longitudinal welding residual tensile stress appears in the center of the weld.

(2) In the vertical direction of the weld, the transverse welding residual tensile stress is larger in the weld and the weld toe, and gradually decreases with the distance from the weld toe increases; the longitudinal welding residual tensile stress reaches the maximum at the center of the weld, and the tensile stress near the weld toe decreases significantly.

\section{REFERENCE}

[1]B.Briekstad, B.L.Josefson. Aparametric study of residual stresses in multi-pass butt-welded stainless steelpipes. International Journal of Pressure Vessels and Piping, 1998, 75(1): 11-25.

[2] Tak K. Lee, Yong Y. Nam, Seung H. Han and Byung C. Shin. A new model for the fatigue life prediction considering residual stress relaxation. Proceedings of the twelfth (2002) International offshore and polar engineering conference, Kitakyushu, Japan, May 26-31, 2002.

[3]Chin-HyungLee, Kyong-HoChang. Numerical analysis of residual stress in welds of similar or dissimilar steel weldments under superimposed tensile loads. Computational Materials Scienee, 2007, 40(4): 548-556.

[4]Dean Deng. FEM prediction of welding residual stress and distortion in carbon steel considering phase transformation effeets. Materials and Design, 2009, 30(2): 359-366.

[5]Wang Jianhua. Finite element simulation of three-dimensional welding deformation of tubesheet joints. Journal of Welding, 1995, 16(3): $10-20$.

[6]Lu Anli, Shi Qingyu, Zhao Haiyan et al. Three-dimensional finite element numerical simulation of temperature and stress fields in thick plate welding process. China Mechanical Engineering, 2001, 12(2): $183-186$

[7]C. G. Matos, R. H. Dodds. Modeling the effects of residual stresses on defects in welds of steel frame connection. Engineering Structures[J], 2000, 22: 1103-1120.

[8]Sun Wenting. Numerical prediction and comparative experimental study on welding residual stress in closure of submarine general segment China Ship Science Research Center, 2006.

[9]Sun Wenting, Wan Zhengquan. Finite element analysis of residual stress in butt welding. Marine Mechanics, 2007, 11 (1): 94-101.

Qianqian Jia, School of Naval Architecture and Ocean Engineering, Jiangsu University of Science and Technology, Zhenjiang 212003, China.

Gong Chen, School of Naval Architecture and Ocean Engineering, Jiangsu University of Science and Technology, Zhenjiang 212003, China. 